DOI: https://doi.org/10.47405/mjssh.v6i10.1116

\begin{tabular}{|c|c|}
\hline & Malaysian Journal of Social Sciences and Humanities (MJSSH) \\
\hline Malaysian Journal of & Volume 6, Issue 10, October 2021 \\
\hline (Mulssh) & e-ISSN : 2504-8562 \\
\hline & $\begin{array}{l}\text { Journal home page: } \\
\text { www.msocialsciences.com }\end{array}$ \\
\hline
\end{tabular}

\title{
Pencapaian Awal Matematik Kanak-kanak mengikut Tempoh Berada di Prasekolah dan Jantina
}

\author{
Connie Cassy Ompok ${ }^{1}$ \\ 1Faculty of Psychology and Education, Universiti Malaysia Sabah (UMS), Malaysia \\ Correspondence: Connie Cassy Ompok (connieompok@ums.edu.my)
}

\begin{abstract}
Abstrak
Kajian ini bertujuan untuk mengenal pasti tahap pencapaian awal Matematik kanak-kanak, mengenal pasti kesan tempoh di prasekolah dan jantina terhadap pencapaian awal Matematik dalam kalangan kanak-kanak prasekolah. Instrumen kajian ini merupakan Pencapaian Awal Matematik (Ginsburg \& Baroody, 2003) berdasarkan Kurikulum Standard Prasekolah Kebangsaan. Seramai 1108 orang kanakkanak prasekolah yang berumur $4+$ dan $5+$ terlibat dalam kajian ini. Statistik deskriptif, ujian-t bebas dan ujian Ancova menggunakan SPSS versi-21 dengan markah ujian pra sebagai kovariat digunakan. Dapatan kajian menunjukkan pencapaian awal Matematik kanak-kanak berada pada tahap purata dan tidak terdapat perbezaan yang signifikan dalam pencapaian awal Matematik kanak-kanak mengikut jantina. Terdapat perbezaan yang signifikan dalam pencapaian awal Matematik kanak-kanak mengikut tempoh di prasekolah. Kajian lanjutan tentang tempoh berada di prasekolah terhadap pencapaian awal Matematik diperlukan untuk menjelaskan dapatan ini.
\end{abstract}

Kata kunci: pencapaian awal matematik, tempoh berada di prasekolah, jantina, kanak-kanak prasekolah

\section{Early Achievement in Children's Mathematics by Duration in Preschool and Gender}

\begin{abstract}
The purpose of this study was to identify the level of early Mathematics performance, effects of independent variables (duration in preschool and gender) towards early Mathematics achievement of preschool children. The instrument used in this research was the "Ujian Pencapaian Awal Matematik" (Ginsburg and Baroody, 2003) based on the National Standard Preschool Curriculum Malaysia. This study was based on quantitative design consisting of 1108 preschool children from national preschool children in Tuaran district, Sabah. For the purpose of data analysis, descriptive statistics, independent ttest and ANCOVA with SPSS ver-21 by considering marks of pre-test as covariate were used. The findings showed that the level of the preschoolers' early Mathematics performance was average and there were no significant differences in their early Mathematics achievement based on gender. However, there were significant differences in early Mathematics achievement based on the duration in preschool. The role of duration in preschool in Mathematics achievement needed further investigations in future studies to clarify the inconclusive findings of this research.
\end{abstract}

Keywords: early mathematics performance, gender, duration in preschool, pre-schoolers 


\section{Pengenalan}

Pencapaian pelajar dalam bidang Sains dan menjadi tumpuan dalam hala tuju pendidikan negara Malaysia. Bak kata pepatah Cina yang ada menyebut, "one generation plants the trees; another gets the shade". Pepatah ini memberi pengertian yang amat jelas iaitu pendidikan awal kanak-kanak memberikan manfaat kepada kanak-kanak itu sendiri malah kepada negara. Menurut Pound (2008), pemikiran Matematik menyumbang kepada kebolehan kanak-kanak untuk mengira, berkomunikasi dan berfikir secara praktikal tentang dunia. Banyak intervensi dalam Matematik kanak-kanak dijalankan di Malaysia sejak kebelakangan ini seperti kajian Ompok et al. (2020), Ompok dan Bacotang (2019), Ling, Pang, Ompok (2018), Ompok, Mei Teng dan Sapirai (2021), Ompok et al. (2018) dan kajian yang dijalankan oleh Ompok, Doig dan Tambagas, (2019).

Di Malaysia, Akta Pendidikan 550 memberi peluang kepada kanak-kanak yang berumur 4+ hingga 5+ tahun untuk mengikuti pendidikan prasekolah (Mohd. Farid et al., 2010). Akta ini menyebabkan terdapat kanak-kanak yang mempunyai tempoh berbeza di prasekolah. Misalnya, kanak-kanak yang berumur 5+ pada tahun semasa dan pernah mengikuti pendidikan prasekolah pada tahun sebelumnya merupakan kanak-kanak tahun dua di prasekolah pada tahun semasa. Namun begitu, tidak semestinya seorang kanak-kanak yang berumur 5+ merupakan kanak-kanak tahun dua pada tahun semasa kerana kanak-kanak tersebut hanya mengikuti pendidikan prasekolah pada tahun semasa. Dalam pengurusan pengambilan kanak-kanak prasekolah di Malaysia, keutamaan akan diberikan kepada mereka yang berumur 5+ dan sekiranya masih terdapat kekosongan, peluang akan diberikan kepada kanak-kanak yang berumur 4+. Mengikut Burkam et al. (2007), kanak-kanak yang memasuki tadika pada usia yang lebih muda akan berisiko mengulang di tadika. Dalam konteks di Malaysia, pengekalan di prasekolah yang mengakibatkan berada di prasekolah dalam tempoh berbeza bukannya berpunca daripada pencapaian yang rendah sepertimana segelintir masyarakat beranggapan bahawa kanak-kanak tahun satu dianggap sebagai belum menguasai. Kajian tentang berbeza tempoh di prasekolah perlu dikaji untuk mengenal pasti kesan Akta Pendidikan.

Banyak kajian yang mencadangkan bahawa pelaburan dalam intervensi pendidikan awal kanak-kanak menawarkan pulangan yang tinggi kepada masyarakat (Heckman et al., 2010; Karoly, Kilburn \& Cannon, 2005). Pembuat dasar dengan sumber yang terhad mungkin tertanya-tanya, mengapa terdapat kanak-kanak tahun satu (P1) dan tahun dua (P2) di prasekolah? Adakah terdapat perbezaan antara P1 (satu tahun di prasekolah) dan P2 (dua tahun di prasekolah) dan jantina terhadap pencapaian awal Matematik? Kajian ini dilaksanakan bertujuan untuk mengenal pasti tahap pencapaian awal Matematik dalam kalangan kanak-kanak prasekolah kebangsaan di daerah Tuaran, Sabah. Kajian ini juga membandingkan pengaruh tempoh di prasekolah dan jantina terhadap pencapaian awal Matematik. Hasil kajian memantapkan lagi jawapan yang telah diperoleh daripada kajian-kajian lepas dan juga memberikan jawapan baharu kepada persoalan yang belum terjawab sebelum ini.

\section{Objektif Kajian}

Kajian ini ialah kesan penggunaan kaedah permainan, buku nombor dan lembaran kerja terhadap pencapaian awal Matematik dalam kalangan kanak-kanak prasekolah kebangsaan di daerah Tuaran, Sabah. Ia dikaji melalui objektif-objektif yang berikut:

i. Mengenal pasti tahap pencapaian awal Matematik selepas program intervensi dalam kalangan kanak-kanak prasekolah kebangsaan di daerah Tuaran, Sabah.

ii. Membandingkan perbezaan min markah pencapaian awal Matematik antara kanak-kanak prasekolah perempuan dan lelaki dalam kalangan kanak-kanak prasekolah P1.

iii. Membandingkan perbezaan min markah pencapaian awal Matematik antara kanak-kanak prasekolah perempuan dan lelaki dalam kalangan kanak-kanak prasekolah P2.

iv. Membandingkan perbezaan min markah pencapaian awal Matematik antara kanak-kanak prasekolah perempuan dan lelaki. 
v. Membandingkan perbezaan min markah pencapaian awal Matematik antara kanak-kanak prasekolah P1 dan P2 dengan mengawal markah Matematik sebelum intervensi.

vi. Membandingkan perbezaan min markah pencapaian awal Matematik antara kanak-kanak prasekolah perempuan dan lelaki dengan mengawal markah Matematik sebelum intervensi.

\section{Hipotesis Kajian}

$\mathrm{H}_{\mathrm{o}} 1$ Tidak terdapat perbezaan yang signifikan pada min markah pencapaian awal Matematik antara kanak-kanak prasekolah perempuan dan lelaki dalam kalangan kanak-kanak prasekolah P1.

$\mathrm{H}_{\mathrm{o}} 2$ Tidak terdapat perbezaan yang signifikan pada min markah pencapaian awal Matematik antara kanak-kanak prasekolah perempuan dan lelaki dalam kalangan kanak-kanak prasekolah P2.

$\mathrm{H}_{0} 3$ Tidak terdapat perbezaan yang signifikan pada min markah pencapaian awal Matematik antara kanak-kanak prasekolah perempuan dan lelaki.

$\mathrm{H}_{0} 4$ Tidak terdapat perbezaan yang signifikan pada min markah pencapaian awal Matematik antara kanak-kanak prasekolah P1 dan P2 dengan mengawal markah Matematik sebelum intervensi.

$\mathrm{H}_{0} 5$ Tidak terdapat perbezaan yang signifikan pada min markah pencapaian awal Matematik antara kanak-kanak prasekolah perempuan dan lelaki dengan mengawal markah Matematik sebelum intervensi.

\section{Sorotan Kajian}

\section{Tahap Pencapaian Awal Matematik}

Kajian tentang tahap pencapaian awal Matematik di Malaysia masih baharu. Setakat ini, hanya satu kajian yang mengenal pasti tahap pencapaian awal Matematik yang menggunakan kanak-kanak sebagai responden. Kajian Rohaty (2012) misalnya, beliau telah menjalankan kajian di enam buah prasekolah yang dianjurkan oleh KPM di kawasan perumahan bandar di Selangor yang melibatkan sebanyak 138 orang kanak-kanak prasekolah. Hasil kajian menunjukkan bahawa tahap pencapaian kanak-kanak melebihi purata min. Walau bagaimanapun, kajian beliau telah ditadbir dengan menggunakan kertas dan pensel yang dianggap tidak sesuai untuk menilai kebolehan Matematik kanak-kanak dan mengenal pasti perkembangan mereka.

\section{Pengaruh Tempoh di Prasekolah terhadap Pencapaian Awal Matematik}

Banyak kajian menunjukkan bahawa jangka masa yang lebih lama di prasekolah memberikan kesan positif berbanding dengan tempoh yang pendek. Dapatan kajian oleh Gullo dan Burton (1992), Dong (2010), Arteaga et al. (2014), Reynolds (1995), Khalid et al. (2013) dan Vandecandelaere et al. (2014) menyokong dapatan kajian-kajian yang dijalankan oleh Bickel, Zigmond dan Strayhorn (1991), Barnett dan Lamy (2006) dan Loeb et al. (2007) iaitu tempoh yang lebih lama lebih baik berbanding dengan tempoh yang pendek. Kajian Hong dan Raudenbush (2005, 2006) dan Hong dan Yu (2007) turut merumuskan bahawa amalan pengekalan di tadika menunjukkan pencapaian yang lebih baik pada akhir tahun rawatan. Dalam erti kata lain, kanak-kanak yang lebih muda tidak mendapat faedah daripada pendidikan awal (DiPasquale, Moule \& Flewelling, 1980; Robinson, 1986; Warder, 1999). Setakat ini, kajian lain yang pernah dijalankan ialah tempoh berada di prasekolah dan pencapaian awal matematik (Ompok et al., 2016) tetapi kajian ini tidak mengambil kira kanak-kanak P1 atau P2. Kajian jenis Prasekolah dan pencapaian awal Matematik juga pernah dijalankan oleh Ompok (2016).

\section{Pengaruh Jantina terhadap Pencapaian Awal Matematik}

Dapatan kajian oleh Arnold et al. (2002), Palejwala dan Fine (2015), dan Lonnemann et al. (2013) menunjukkan bahawa kanak-kanak sejak dari kecil lagi telah pun menunjukkan perbezaan dalam pencapaian dalam Matematik dan banyak kajian percaya bahawa murid lelaki adalah lebih baik berbanding dengan murid perempuan (Maccoby \& Jacklin, 1974). Sebaliknya, dapatan kajian Rosazizi 
(2004), Rohaty (2012), Lachance dan Mazzocco (2006) serta Lee et al. (2010) mendapati tidak terdapat perbezaan dalam pencapaian mengikut jantina pada peringkat awal persekolahan. Kajian lanjutan adalah diperlukan untuk menambahkan bukti empirikal yang sedia ada.

\section{Metod Kajian}

Kajian ini melibatkan 1108 orang kanak-kanak prasekolah kebangsaan di daerah Tuaran sebagai sampel kajian yang mengikuti tiga kumpulan rawatan mengikut kaedah mengajar, iaitu kumpulan permainan $(\mathrm{N}=382)$, kumpulan buku nombor $(\mathrm{N}=349)$, dan kumpulan lembaran kerja $(\mathrm{N}=377)$. Pencapaian dalam ujian pasca kanak-kanak melalui temu bual direkodkan dan diterjemahkan kepada data kuantitatif. Dalam kajian ini, penyelidik telah membina dua set instrumen pencapaian awal Matematik kanak-kanak prasekolah yang diadaptasikan daripada Test of Early Mathematics Ability (TEMA) (Ginsburg \& Baroody, 2003) berdasarkan KSPK.

\section{Hasil Kajian}

\section{Populasi dan Responden Kajian}

Jadual 1 memaparkan keputusan bilangan kanak-kanak mengikut tempoh di prasekolah. Seramai 49.82\% iaitu 552 orang responden terdiri daripada kanak-kanak P1. Sebanyak 50.18\% iaitu 556 orang responden terdiri daripada kanak-kanak $\mathrm{P} 2$.

Jadual 1: Bilangan kanak-kanak prasekolah mengikut tempoh di prasekolah

\begin{tabular}{lcc}
\hline Tempoh di prasekolah & Frekuensi & Peratus \% \\
\hline P1 & 552 & 49.82 \\
P2 & 556 & 50.18 \\
Jumlah & 1108 & 100 \\
\hline
\end{tabular}

Seramai 1108 orang responden dan 46 orang guru pendidikan awal kanak-kanak terlibat dalam kajian ini di daerah Tuaran, Sabah. Jadual 2 membincangkan profil kajian melibatkan frekuensi dan peratus yang terdiri tempoh di prasekolah dan jantina.

Jadual 2 : Bilangan kanak-kanak prasekolah mengikut jantina

\begin{tabular}{lcc}
\hline Jantina & Frekuensi & Peratus \% \\
\hline Perempuan & 561 & 50.63 \\
Lelaki & 547 & 49.37 \\
Jumlah & 1108 & 100 \\
\hline
\end{tabular}

\section{Tahap Pencapaian Awal Matematik}

Jadual 3 memaparkan maklumat pencapaian awal Matematik kanak-kanak prasekolah yang terlibat dalam kajian ini. Terdapat tiga tahap pencapaian iaitu di bawah purata, purata dan atas purata. Min skor pada tahap bawah purata berada dalam lingkungan $0-60$, min skor pada tahap purata berada dalam lingkungan 60-80 dan min skor pada tahap atas purata berada dalam lingkungan 80-100. Skor min kanak-kanak yang mengikuti kajian ini ialah 68.07 dengan sisihan piawai 21.44. Ini menunjukkan pencapaian awal Matematik kanak-kanak dalam kajian ini selepas program intervensi dijalankan berada pada tahap purata. 
DOI: https://doi.org/10.47405/mjssh.v6i10.1116

Jadual 3: Statistik deskriptif pencapaian awal Matematik kanak-kanak prasekolah

\begin{tabular}{llll}
\hline Pemboleh ubah & Bilangan & Min & Sisihan piawai \\
\hline Pencapaian awal Matematik & 1108 & 68.07 & 21.44 \\
\hline
\end{tabular}

\section{Adakah Terdapat Perbezaan Yang Signifikan Pada Min Markah Pencapaian Awal Matematik Antara kanak-kanak Prasekolah Perempuan dan Lelaki Dalam Kalangan Kanak-kanak Prasekolah P1?}

$\mathrm{H}_{0} 1$ Tidak terdapat perbezaan yang signifikan pada min markah pencapaian awal Matematik antara kanak-kanak prasekolah perempuan dan lelaki dalam kalangan kanak-kanak prasekolah P1.

Jadual 4 memaparkan keputusan ujian-t bebas. Keputusan menunjukkan $t(d f)=0.62, k>.05$. Oleh itu, hipotesis nul gagal untuk ditolak. Ini bermaksud tidak terdapat perbezaan yang signifikan dalam pencapaian awal Matematik antara kanak-kanak prasekolah perempuan $(\min =60.66)$ dan lelaki $(\min =$ 59.55) dalam kalangan kanak-kanak prasekolah P1.

Jadual 4: Skor pencapaian awal Matematik antara kanak-kanak prasekolah perempuan dan lelaki dalam kalangan kanak-kanak prasekolah P1

\begin{tabular}{llllll}
\hline Jantina & Bilangan & Min & $\begin{array}{l}\text { Sisihan } \\
\text { Piawai }\end{array}$ & $\begin{array}{l}\text { t- } \\
\text { value }\end{array}$ & Sig.level \\
\hline Perempuan & 271 & 60.66 & 21.21 & .62 & .54 \\
Lelaki & 281 & 59.55 & 21.40 & & \\
\hline
\end{tabular}

\section{Adakah Terdapat Perbezaan Yang Signifikan Pada Min Markah Pencapaian Awal Matematik Antara Kanak-kanak Prasekolah Perempuan dan Lelaki Dalam Kalangan Kanak-kanak Prasekolah P2?}

$\mathrm{H}_{0} 2$ Tidak terdapat perbezaan yang signifikan pada min markah pencapaian awal Matematik antara kanak-kanak prasekolah perempuan dan lelaki dalam kalangan kanak-kanak prasekolah P2.

Jadual 5 memaparkan keputusan ujian-t bebas. Keputusan menunjukkan $\mathrm{t}(\mathrm{df})=0.88, \mathrm{k}>.05$. Oleh itu, hipotesis nul gagal untuk ditolak. Ini bermaksud tidak terdapat perbezaan yang signifikan dalam pencapaian awal Matematik antara kanak-kanak prasekolah perempuan $(\min =76.68)$ dan lelaki $(\min =73.30)$ dalam kalangan kanak-kanak prasekolah P2.

Jadual 5: Skor pencapaian awal Matematik antara kanak-kanak prasekolah perempuan dan lelaki dalam kalangan kanak-kanak prasekolah P2

\begin{tabular}{llllll}
\hline Jantina & Bilangan & Min & $\begin{array}{l}\text { Sisihan } \\
\text { piawai }\end{array}$ & $\begin{array}{l}\text { t- } \\
\text { value }\end{array}$ & Sig.level \\
\hline Perempuan & 276 & 76.68 & 17.06 & .88 & .38 \\
Lelaki & 280 & 73.30 & 19.72 & & \\
\hline
\end{tabular}

\section{Adakah Terdapat Perbezaan Yang Signifikan Pada Min Markah Pencapaian Awal Matematik Antara Kanak-kanak Prasekolah Perempuan dan Lelaki?}

$\mathrm{H}_{0} 3$ Tidak terdapat perbezaan yang signifikan pada min markah pencapaian awal Matematik antara kanak-kanak prasekolah perempuan dan lelaki.

Jadual 6 memaparkan keputusan ujian-t bebas. Keputusan menunjukkan $t(d f)=1.03, k>.05$. Oleh itu, hipotesis nul gagal untuk ditolak. Ini bermakna tidak terdapat perbezaan yang signifikan dalam 
DOI: https://doi.org/10.47405/mjssh.v6i10.1116

pencapaian awal Matematik antara kanak-kanak prasekolah lelaki $(\min =67.41)$ dan perempuan $(\mathrm{min}=$ 68.74).

Jadual 6: Skor pencapaian awal Matematik antara kanak-kanak prasekolah perempuan dan lelaki

\begin{tabular}{llllll}
\hline Jantina & Bilangan & Min & $\begin{array}{l}\text { Sisihan } \\
\text { piawai }\end{array}$ & t-value & Sig.level \\
\hline Perempuan & 547 & 68.74 & 20.82 & 1.03 & .30 \\
Lelaki & 561 & 67.41 & 20.02 & & \\
\hline
\end{tabular}

\section{Adakah Terdapat Perbezaan Yang Signifikan Pada Min Markah Pencapaian Awal Matematik Antara Kanak-kanak Prasekolah P1 dan P2 Dengan Mengawal Markah Matematik Sebelum Intervensi?}

$\mathrm{H}_{\mathrm{o}} 4$ Tidak terdapat perbezaan yang signifikan pada min markah pencapaian awal Matematik antara kanak-kanak prasekolah P1 dan P2 dengan mengawal markah Matematik sebelum intervensi.

Jadual 7 memaparkan keputusan Tests of Between-Subjects Effects bagi $\mathrm{H}_{0} 4$. Keputusan ujian ANCOVA menunjukkan bahawa terdapat kesan yang signifikan berkenaan tempoh di prasekolah terhadap pencapaian awal Matematik dalam kalangan kanak-kanak $[F(1,1105)=66.45, \mathrm{p}<.05]$. Keputusan menunjukkan, dengan mengawal pencapaian pra responden kajian, tempoh di prasekolah mempengaruhi pencapaian pasca responden secara signifikan. Berdasarkan keputusan ini, penyelidik menolak hipotesis nul.

Jadual 7: Tests of Between-Subjects Effects

\begin{tabular}{llllll}
\hline Source & Type III Sum of Squares & Df & Mean Square & F & Sig. \\
\hline Corrected Model & $203171.02^{\mathrm{a}}$ & 2 & 101585.51 & 367.34 & .00 \\
Intercept & 297435.02 & 1 & 297435.02 & 1075.54 & .00 \\
UPRA & 133235.11 & 1 & 133235.11 & 481.78 & .00 \\
Tempoh di & 18376.88 & 1 & 18376.88 & 66.45 & .00 \\
prasekolah & & & & & \\
Error & 305583.27 & 1105 & 276.55 & & \\
Total & 5642487.50 & 1108 & & & \\
Corrected Total & 508754.29 & 1107 & & & \\
\hline
\end{tabular}

Dependent Variable: UPASCA

a. $R$ Squared $=.399$ (Adjusted $R$ Squared $=.398)$

\section{Adakah Terdapat Perbezaan Yang Signifikan Pada Min Markah Pencapaian Awal Matematik Antara Kanak-kanak Prasekolah Perempuan dan Lelaki Dengan Mengawal Markah Matematik Sebelum Intervensi?}

$\mathrm{H}_{0} 5$ Tidak terdapat perbezaan yang signifikan pada min markah pencapaian awal Matematik antara kanak-kanak prasekolah perempuan dan lelaki dengan mengawal markah Matematik sebelum intervensi.

Jadual 8 memaparkan keputusan Tests of Between-Subjects Effects bagi $\mathrm{H}_{0} 5$. Keputusan ujian ANCOVA menunjukkan bahawa tidak terdapat kesan yang signifikan jantina terhadap pencapaian awal Matematik dalam kalangan kanak-kanak $[F(1,1105)=0.22, \mathrm{p}>.05]$. Keputusan menunjukkan, dengan mengawal pencapaian pra responden kajian, jantina tidak mempengaruhi pencapaian awal Matematik responden secara signifikan. Berdasarkan keputusan ini, penyelidik gagal untuk menolak hipotesis nul. 
Jadual 8 : Tests of Between-Subjects Effects

\begin{tabular}{llcccc} 
Source & Type III Sum of Squares & Df & Mean Square & F & Sig. \\
\hline Corrected & $184857.80^{\mathrm{a}}$ & 2 & 92428.90 & 315.33 & .00 \\
Model & & & & & \\
Intercept & 279557.82 & 1 & 279557.82 & 953.74 & .00 \\
UPRA & 184366.22 & 1 & 184366.22 & 628.98 & .00 \\
Jantina & 63.67 & 1 & 63.67 & .22 & .64 \\
Error & 323896.48 & 1105 & 293.12 & & \\
Total & 5642487.50 & 1108 & & & \\
Corrected Total & 508754.29 & 1107 & & & \\
\hline
\end{tabular}

Dependent Variable: UPASCA

a. $R$ Squared $=.363$ (Adjusted $R$ Squared $=.362)$

\section{Perbincangan}

Dalam kajian ini, tahap pencapaian awal Matematik dalam kalangan kanak-kanak prasekolah kebangsaan di daerah Tuaran, Sabah berada pada tahap purata. Hasil kajian ini mendapati bahawa min markah pencapaian awal Matematik adalah lebih rendah daripada dapatan kajian yang pernah dijalankan oleh Rohaty (2012) yang menunjukkan bahawa pencapaian awal Matematik berada pada atas purata. Keadaan ini mungkin disebabkan perbezaan seperti ciri demografi, ujian pencapaian yang berbeza dan sebagainya. Selain itu, nilai sisihan piawai yang tinggi menunjukkan kemungkinan guru perlu mempelbagaikan kaedah mengajar. Dengan menggunakan ujian-t bebas, dapatan kajian memaparkan bahawa tidak terdapat perbezaan yang signifikan pada min markah pencapaian awal Matematik antara kanak-kanak perempuan dan lelaki dalam kalangan kanak-kanak P1. Dapatan kajian juga menunjukkan dengan menggunakan ujian-t bebas, tidak terdapat perbezaan yang signifikan pada min markah pencapaian awal Matematik antara kanak-kanak perempuan dan lelaki dalam kalangan kanak-kanak P2. Secara keseluruhannya, dapatan kajian ujian-t bebas dan ujian ANCOVA menunjukkan bahawa tidak terdapat perbezaan yang signifikan pada min markah pencapaian awal Matematik mengikut jantina tetapi berbeza mengikut tempoh berada di prasekolah. Perbezaan jantina dalam pencapaian awal Matematik tidak wujud dalam kajian ini. Dapatan kajian ini menyokong kajian di Malaysia seperti Rosazizi (2004) dan Rohaty (2012) yang gagal menunjukkan perbezaan jantina pada peringkat kanak-kanak prasekolah.

\section{Kesimpulan}

Tahap pencapaian awal Matematik kanak-kanak prasekolah kebangsaan di daerah Tuaran berada pada tahap purata. Tidak terdapat perbezaan dalam pencapaian awal Matematik mengikut jantina dalam kalangan kanak-kanak P1 dan begitu juga dalam kalangan kanak-kanak P2. Tidak terdapat perbezaan dalam pencapaian awal Matematik mengikut jantina tetapi pencapaian awal Matematik kanak-kanak lelaki lebih rendah berbanding dengan kanak-kanak perempuan. Tempoh berapa di prasekolah memberi kesan kepada pencapaian awal Matematik. Kajian lanjutan adalah diperlukan.

\section{Rujukan}

Arnold, D.H., Fisher, P.H., Doctoroff, G.L., \& Dobbs, J. 2002. Accelerating Math development in Head Start classrooms. Journal of Educational Psychology, 94(4),762-770.

Arteaga, I., Humpage, S., Reynolds, A.J., \& Temple, J.A. (2014). One year of preschool or two: Is it important for adult outcome? Economic of Education Review, 40, 221-237. 
Barnett, W.S., \& Lamy, C.E. (2006). Estimated impacts of number of years of preschool attendance on vocabulary, literacy and Math skills at kindergarten entry. New Brunswick: National Institute for Early Educator Research.

Bickel, D.D., Zigmond, N., \& Strayhorn, J. (1991). Chronological age at entrance to first grade, effect on elementary school success. Early Childhood Research Quarterly, 6, 105-117.

Burkam, D.T., LoGerfo, L., Ready, D., \& Lee, V.E. (2007). The differential effects of repeating kindergarten. Journal of Education for Students Placed at Risk, 12(2), 103-136.

Dong, Y.Y. (2010). Kept back to get ahead? Kindergarten retention and academic performance. European Economic Review, 54(2), 219-236.

Ginsburg, H.P., \& Baroody, A.J. (2003). Test of early Mathematics ability (3 ${ }^{\text {rd }}$ edition) Austin: PROED SAGE Publications.

Gullo, D.F., \& Burton, C.B. (1992). Age of entry, preschool experience, and sex as antecedents of academic readiness in kindergarten. Early Childhood Research Quarterly, 7, 175-186.

Heckman, J.J., Moon, S.H., Pinto, R., Savelyev, P., \& Yavitz, A. (2010). The rate of return to the High Scope Perry Preschool Program. Journal of Public Economics, 94, 114-128.

Hong, G., \& Raudenbush, S.W. (2005). Effects of kindergarten retention policy on children's cognitive growth in reading and Mathematics. Educational Evaluation and Policy Analysis, 27(3), 205-224.

Hong, G., \& Raudenbush, S.W. (2006). Evaluating kindergarten retention policy: A case study of causal inference for multilevel observational data. Journal of the American Statistical Association,101(475), 901-910.

Hong, G., \& Yu, B. (2007). Early-grade retention and children's reading and Math learning in elementary years. Educational Evaluation and Policy Analysis, 29(4), 239-261.

Karoly, L., Kilburn, M.R., \& Cannon, J.S. (2005). Early childhood interventions: Proven results, future promise. Santa Monica: RAND Corporation.

Khalid, R., Rana, S., Muhammad, Z.I., \& Nousheen, K. (2013). Preschool attendees and nonpreschool attendees. Academic achievement and social skills. Interdisciplinary Journal of Contemporary Research in Business, 4(9), 1146-1157.

Lachance, J.A., \& Mazzocco, M.M.M. (2006). A longitudinal analysis of sex differences in Math and spatial skills in primary school age children. Learning and Individual Differences, 16, 195-216.

Lee, J., Fox, J., \& Brown, A.L. (2010). Content analysis of children's Mathematics proficiency. Education and Urban Society Published, 43, 627-641.

Loeb, S., Bridges, M., Bassok, D., Fuller, B., \& Rumberger, R.W. (2007). How much is too much? The influence of preschool centers on children's social and cognitive development. Economics of Education Review, 26(1), 52-66.

Lonnemann, J., Linkersdörfer, J., Hasselhorn, M., \& Lindberg, S. (2013). Gender differences in both tails of the distribution of numerical competencies in preschool children. Educ Stud Math, 84, 201-208.

Maccoby, E.E., \& Jacklin, C.N. (1974). The psychology of sex differences. Stanford: Stanford University Press.

Mohd. Farid Zakaria, Muhammad Azizi Che Rusli, Mohd. Norhazril Mohd. Kamarulzaman, Sharifah Ahmad dan Rodmawati Ismail. 2010. Halatuju pendidikan awal kanak-kanak di Malaysia. Fakulti Pendidikan Teknikal dan Vokasional, Universiti Pendidikan Sultan Idris.

Ompok, C.C., Pang., Mun, H.C., \& Chin, K. E.. (2016). Tempoh Berada di Prasekolah dan Pencapaian Awal Matematik. International Academic Research Journal. http://www.iarjournal.com/wp-content/uploads/IARJ-SS-20161-6-14.pdf

Ompok, C.C. (2016). Jenis Prasekolah dan pencapaian awal Matematik. International Academic Research Journal. http://www.iarjournal.com/wp-content/uploads/IARJ-SS-20162-24-30.pdf

Ompok, C. S. @ C. C., Ling, M. T., Abdullah, S. N. M. @ S., Tambagas, M., Tony, E. E., \& Said, N. (2020). Mentor-mentee programme for STEM education at preschool level. Southeast Asia Early Childhood Journal, 9(1), 1-14. Retrieved from https://ejournal.upsi.edu.my/index.php/SAECJ/article/view/3147

Ompok, C. S. @ C. C., \& Bacotang, J. (2019). Kesan kaedah mengajar terhadap pencapaian awal matematik dalam kalangan kanak-kanak prasekolah. Jurnal Pendidikan Awal Kanak-Kanak Kebangsaan, 8, 8-16. https://doi.org/10.37134/jpak.vol8.2.2019 
Ling MT., Pang V., Ompok C.C. (2018). Measuring Change in Early Mathematics Ability of Children Who Learn Using Games: Stacked Analysis in Rasch Measurement. In: Zhang Q. (eds) Pacific Rim Objective Measurement Symposium (PROMS) 2016 Conference Proceedings. Springer, Singapore. https://doi.org/10.1007/978-981-10-8138-5 17

Ompok, C. S. @ C. C., Mei Teng, L., \& Sapirai, J. (2021). Effect of games towards children's mathematics performance. Southeast Asia Early Childhood Journal, 10(1), 1-17. https://doi.org/10.37134/saecj.vol10.1.1.2021

Ompok, C., Teng, L., Pang, V., Mun, H., Abdullah, A., \& Sapirai, J. (2018). Early mathematics learning in reading and writing numerals: Learning through "What are the numbers?" A picture book made up of Flora and Fauna in Borneo. Southeast Asia Early Childhood Journal, 7, 52-59. https://doi.org/10.37134/saecj.vol7.6.2018

Ompok, C.C., Doig, B. \& Tambagas, M. (2019). Patterns of Young Children's Number Sense Development as Assessed by How Many Hidden Game. Journal of Cognitive Sciences and Human Development, 4(2). DOI: 10.33736/icshd.1117.2018

Palejwala, M.H., \& Fine, J.G. (2015). Gender differences in latent cognitive abilities in children aged 2 to 7 . Intelligence, $48,96-108$.

Pound, L. (2008). Thinking and learning about Mathematics in the early years. Abingdon: Routledge.

Reynolds, A.J. (1995). One year of preschool intervention or two: Does it matter? Early Childhood Research Quarterly, 10(1), 1-31.

Robinson, S.L. (1986). School entrance age and the three R's research, reality and recommendations. Kappa Delta Pi Record, 3, 3-7.

Rohaty Mohd. Majzub. (2012). Preschool children's early Mathematics achievement based on gender and ethnicity. Asian Social Science, 8(16), 24-29.

Rosazizi Abd. Rahim. (2004). Keberkesanan penggunaan perisian rangsangan komputer ke atas kebolehan matematik kanak-kanak prasekolah. Tesis Sarjana. Universiti Putra Malaysia.

Vandecandelaere, M., Schmitt, E., Vanlaar, G., Fraine, B.D., \& Damme, J.V. (2014). Effects of kindergarten retention for at-risk children's Mathematics development. Research Papers in Education.

Warder, K. (1999). "Born in December, ready for school?" in http:www.eric.ed.gov/ERICWebPortal/contentdelivery/servlet/ERICServlet?accno=ED439815. Retrived 20 October 2012. 